\title{
Genetic structuring and gene flow in a hybrid zone between two chromosome races of the common shrew (Sorex araneus, Insectivora) revealed by microsatellites
}

\author{
A. WYTTENBACH*, Y. NARAIN \& K. FREDGA \\ Department of Genetics, Uppsala University, Box 7003, SE-750 07 Uppsala, Sweden
}

\begin{abstract}
Hybrid zones between chromosome races are of interest because they offer the opportunity to investigate the role of chromosomes in speciation processes. Here we study gene flow and finescale genetic structure of a chromosome hybrid zone in the common shrew (Sorex araneus, Insectivora, Mammalia) in central Sweden using six polymorphic microsatellite loci. The centre of the hybrid zone closely follows a river towards which race-specific chromosomes sharply decrease suggesting a physical barrier to introgression. We examined 285 animals from 22 different localities and performed a hierarchical analysis for $F$ and $R$ statistics. Genetic structuring within and between the two chromosome races (Hällefors and Uppsala) was found to be weak, but significant. No positive relationship between geographical and genetic distance was detected, suggesting the absence of isolation by distance. Gene flow between the races is not reduced. Therefore, it does not seem that the river is an important barrier reducing introgression between races. The fact that the width of the hybrid zone is narrow and that its centre follows the river despite high levels of migration is discussed.
\end{abstract}

Keywords: common shrew, gene flow, genetic structure, hybrid zone, microsatellites, Sorex araneus.

\section{Introduction}

Hybrid zones are of particular interest because they offer a unique opportunity to study introgression, maintenance of genetic integrity and thus the process of speciation (Harrison, 1990). Chromosomal hybrid zones are well represented in mammals (Searle, 1993) and relevant to study if chromosomes play a role in speciation processes (e.g. King, 1993). In the common shrew (Sorex araneus, Insectivora, Mammalia), an immense chromosomal variation is found which is caused by Robertsonian (centric) fusion mutations within and between populations (Wojcik \& Searle, 1988). So far, 50 well-defined chromosome races have been described in this species (Zima et al., 1996). Inter-racial hybrid zones have been reported in Britain, the Czech Republic, Sweden, Switzerland, Poland and Siberia (Searle,

*Correspondence and present address: University of Cambridge, Department of Medical Genetics, Box 158, Addenbrooke's Hospital, Hills Road, Cambridge CB2 2QQ, U.K. E-mail: aw237@mole.bio.cam.ac.uk
1993 and references therein; Banaszek, 1994; Lukacova et al., 1994). Therefore, the common shrew is of great interest for the study of karyotypic evolution in mammals. At present, a growing number of Sorex araneus chromosomal hybrid zones are under investigation, but most of these have been examined using chromosomal markers only (e.g. Fedyk et al., 1993; Lukacova et al., 1994; Narain \& Fredga, 1996; Szalay et al., 1996). Three hybrid zones were studied using allozymes and/or mtDNA markers (Frykman \& Bengtsson, 1984; Ratkiewicz et al., 1994; Brünner \& Hausser, 1996). With the exception of the contact zone between the Cordon and Valais races in Switzerland (Lugon-Moulin et al., 1996), no informative results on gene flow and genetic structuring within these hybrid zones are available because nuclear markers used so far for analysis (allozymes) generally show weak genetic variation (Hausser, 1991). Microsatellite markers are now widely used in population genetics and have been shown to provide a sensitive measure to detect patterns of hybridization (e.g. Roy et al., 1994). The recent development of 
polymorphic microsatellites for $S$. araneus (Wyttenbach et al., 1997; Balloux et al., 1998) offers the possibility of studying the genetics of hybrid zones in this species in much more detail. In $S$. araneus, microsatellite loci have been shown to be highly polymorphic, both within and between chromosomal races (Wyttenbach \& Hausser 1996a; Wyttenbach et al., 1997).

The distribution patterns and zone of contact between two chromosome races of $S$. araneus (Uppsala and Hällefors races) in the central part of Sweden were recently described (Narain \& Fredga, 1996). A transect covering $\approx 21 \mathrm{~km}$ across the hybrid zone showed a sharp decrease of race-specific markers (distinct metacentric chromosomes with monobrachial homologies fixed in each race) towards a river. In this way it was demonstrated that the centre of the hybrid zone was closely following the river Kolbäck (Fig. 1). This river is generally 50-60 m wide and sometimes widens into small lakes (see Fig. 1). Around $70 \%$ of the river freezes regularly in winter. The observed cline width calculated from race-specific metacentric chromosomes ( $k o$ and $k p$ ) was as narrow as $2300 \mathrm{~m}$. These observations lead to the question: to what extent might a geographical barrier (river) affect the level of introgression between the two chromosome races? Generally, narrow hybrid zones (such as between the Uppsala and Hällefors races) can be the result of several factors. Selection against hybrids, different habitat preferences of the races, recent secondary contact between the parental forms or the presence of a geographical barrier are all reasons that, alone or in combination, affect the evolution and location of contact zones (Hewitt, 1988). In our case, fertility reduction of hybrid males between the two parental types was shown to be insignificant in a study of some reproductive characteristics (Narain \& Fredga, 1997). However, anaphase I disjunction studies were not carried out and the authors did not consider fertility reduction in females. The habitat in the study area is dominated by forest interspersed by agricultural fields and grassland. It seems that the habitat is homogeneous in the distribution range of both races, particularly in the small area where the two races are hybridizing. Therefore, recent secondary contact or the presence of a geographical barrier (river) are likely factors affecting the width of the hybrid zone between the Uppsala and Hällefors races.

We estimated the level of gene flow between the Uppsala and Hällefors races, analysed the importance of isolation by distance and the impact of the geographical barrier that separates the races

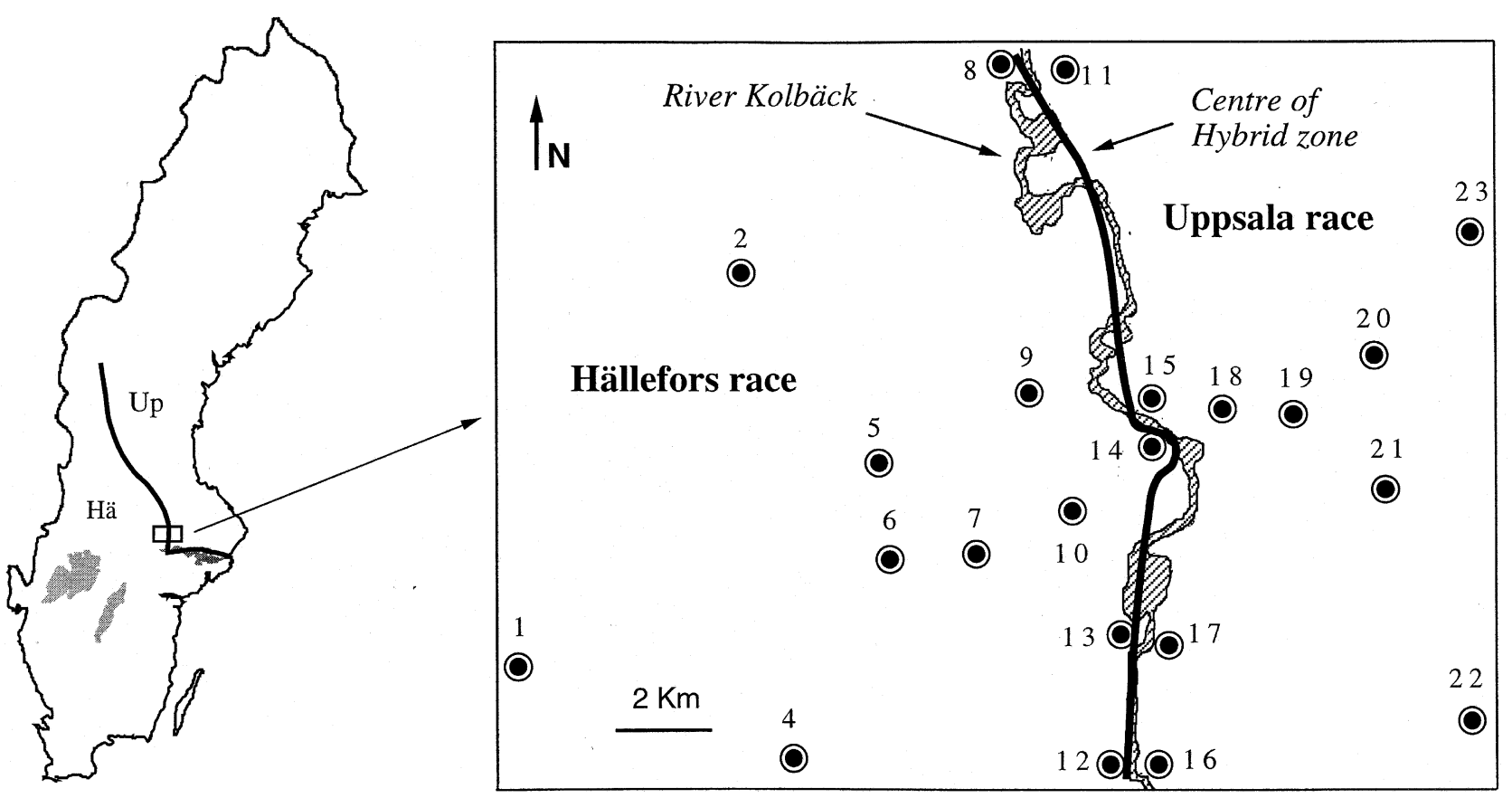

Fig. 1 The sampling area of Surahammar in central Sweden. The centre of the Sorex araneus chromosomal hybrid zone is indicated, as is the river Kolbäck. Numbers above each sampling locality correspond to numbers given in Table 1 . 
(Kolbäck river), using six polymorphic microsatellites. In addition, by analysing the genetic structure within and between chromosome races, using a hierarchical $F$ - and $R$-statistics approach, we tried to unravel the fine-scale genetic configuration of the hybrid zone in order to understand better its present geographical structure and evolution.

\section{Materials and methods}

\section{Biological material}

[For details of the distribution patterns of the two chromosome races and hybrid zone, see Fredga (1996) and Narain \& Fredga (1996).] Tissue samples were obtained from a total of 286 shrews. These animals were previously trapped at 23 localities covering an area of about $400 \mathrm{~km}^{2}$ in the hybrid zone as described by Narain \& Fredga (1996). Individuals collected in 1994-96 were used for analysis. The number of animals scored from each locality ranges from nine to 44 with the exception of locality $4(N=6)$ (Fig. 1 and Table 1). Individuals were karyotyped and their race identified by G-banding (Narain \& Fredga, 1996). In Table 1 the number of animals and their karyotypes is given for each locality.

\section{DNA isolation, amplification and electrophoresis}

DNA samples were obtained by cutting the tip of a digit from frozen animals. Tissue samples were digested in an extraction medium $(200 \mu \mathrm{L})$ consisting of Chelex-100 (5\%), Proteinase $\mathrm{K}(10 \mathrm{mg} / \mathrm{mL})$ and DTT/NaAc $(1 \mathrm{~m} / 0.08 \mathrm{M})$ at $56^{\circ} \mathrm{C}$ overnight. The mixture was then boiled for $8 \mathrm{~min}$ and centrifuged at $2000 \mathrm{~g}$ for $3 \mathrm{~min}$. The supernatant containing DNA was removed and $1 \mu \mathrm{L}$ used for each polymerase chain reaction (PCR). Six microsatellite loci (L9, L14, L16, L45, L67, L92) were used for analysis. Amplification conditions for each locus were performed following Wyttenbach et al. (1997) and Balloux et al. (1998). After amplification, aliquots of the $10 \mu \mathrm{L}$ reaction mixture were mixed with 0.5 volume of formamide loading buffer, heated to $80^{\circ} \mathrm{C}$ for 2 min and run on denaturing polyacrylamide gels (6\%, $8 \mathrm{~m}$ urea). Drying and autoradiography were performed following standard procedures. A sequencing reaction was used as a size marker for reading the band polymorphisms.

Table 1 Number of individuals of the Hällefors race, Uppsala race and hybrids of Sorex araneus analysed from each locality in the area of Surahammar

\begin{tabular}{|c|c|c|c|c|c|}
\hline \multirow{2}{*}{$\begin{array}{l}\text { No. in } \\
\text { Fig. } 1\end{array}$} & \multirow[b]{2}{*}{ Locality } & \multicolumn{4}{|c|}{ Number of specimens } \\
\hline & & Hällefors & Hybrids & Uppsala & Total \\
\hline 1 & Rölö & 10 & 0 & 0 & 10 \\
\hline 2 & Lappkärrsmossen & 8 & 1 & 0 & 9 \\
\hline 4 & Hemlinge north & 5 & 1 & 0 & 6 \\
\hline 5 & Djupmossen & 11 & 0 & 0 & 11 \\
\hline 6 & Skyttorp & 10 & 1 & 0 & 11 \\
\hline 7 & Baståsen & 10 & 1 & 0 & 11 \\
\hline 8 & Seglingbo & 3 & 6 & 2 & 11 \\
\hline 9 & Nybron/Trugsbo & 15 & 3 & 0 & 18 \\
\hline 10 & Elingbo & 10 & 3 & 0 & 13 \\
\hline 11 & Färmansbo & 0 & 1 & 13 & 14 \\
\hline 12 & Laggarsjön & 8 & 4 & 1 & 13 \\
\hline 13 & Ståltorp & 6 & 4 & 1 & 11 \\
\hline 14 & Hedvallsbron & 4 & 6 & 3 & 13 \\
\hline 15 & Rävnäs & 4 & 19 & 20 & 43 \\
\hline 16 & Hallsta mosse & 0 & 1 & 9 & 10 \\
\hline 17 & Framnäs & 0 & 2 & 8 & 10 \\
\hline 18 & Svenskbyn & 0 & 2 & 12 & 14 \\
\hline 19 & Stingsmossen & 0 & 1 & 12 & 13 \\
\hline 20 & Timmermossen & 0 & 2 & 10 & 12 \\
\hline 21 & Bårhuset & 0 & 1 & 9 & 10 \\
\hline 22 & Klockartorp & 0 & 1 & 9 & 10 \\
\hline 23 & Svartkärret & 0 & 0 & 12 & 12 \\
\hline
\end{tabular}

(C) The Genetical Society of Great Britain, Heredity, 82, 79-88. 


\section{Statistical analysis}

Allele frequencies and Hardy-Weinberg exact tests were calculated and performed using the software package FSTAT 2.3 (Goudet, 1995) and GENEPOP 3.1a (Raymond \& Rousset, 1995). Both programs compute $F$-statistics according to Weir \& Cockerham (1984). Observed heterozygosity $\left(H_{\mathrm{o}}\right)$ were calculated by a direct count of band polymorphism, whereas the expected heterozygosity $\left(H_{\mathrm{e}}\right)$ was measured as the gene diversity after Nei (1987). Race-specific microsatellite variants, defined as alleles occurring exclusively in one race, were calculated for each locus, each race and overall.

Temporal variation at microsatellite loci was computed for localities 10 and 20 (Fig. 1) where individuals from two different generations (spring and autumn 1994) were collected. Values of $F_{\mathrm{ST}}$ were used to measure the differentiation between generations and tested for a significant departure from zero with FSTAT. In this way, the distribution of the null hypothesis $\left(F_{\mathrm{ST}}\right.$ not $\left.>0\right)$ is obtained and compared to the observed distribution. The same procedure was applied for localities 14 and 15, where individuals were available from two different years belonging to the same generation (autumn 1994 and spring 1995). Fisher's procedure (Sokal \& Rohlf, 1995) was applied combining the $P$-values across populations. The quantity $-2 \Sigma \ln \left(P_{i}\right)$ was calculated; this quantity is distributed as $\chi^{2}$ with $2 k$ degrees of freedom. $P_{i}$ is the $i$ th value of $k$ observations. To test for genotypic linkage disequilibrium we used GENEPOP 3.1a (Raymond \& Rousset, 1995).

To assess genetic structuring between populations, $F_{\text {IS }}$ (inbreeding coefficient), $F_{\text {ST }}$ (fixation index) and $F_{\text {IT }}$ (overall inbreeding coefficient) were calculated using FSTAT. To test for a significant departure from zero (see above) we used 5000 permutations of alleles within samples $\left(F_{\text {IS }}\right)$ and 5000 permutations of genotypes among samples $\left(F_{\mathrm{ST}}\right)$. Migration can then be estimated following $N m=\left\{\left(1 / F_{\mathrm{ST}}\right)-1 / 4\right\}$. This is the relationship between $N m$ and $F_{\text {ST }}$ expected for neutral alleles in an island model of subdivided populations at migration-drift equilibrium (Wright, 1951). $N$ is the effective size of each population, which is assumed to be constant, and $m$ the proportion of migrants arriving each generation in a population.

Mutational mechanisms associated with microsatellite evolution are debated (for review see Goldstein \& Pollock, 1997). Variation at microsatellite loci can be explained by either an infinite allele size model (IAM) or a stepwise mutation model (SMM). $R_{\mathrm{ST}}$ is an $F_{\mathrm{ST}}$-like estimator of population differentia- tion, derived by Slatkin (1995) and based on the variance in the number of repeats of alleles; that allows a better estimation of genetic differentiation when the mutation pattern of microsatellite loci follows a SMM. Therefore, we also calculated $R$-estimates $\left(R_{\mathrm{IS}}, R_{\mathrm{ST}}\right.$ and $\left.R_{\mathrm{IT}}\right)$ using GENEPOP. Estimates for $F$ - and $R$-statistics were first calculated for each chromosome race separately. For this purpose, sites with animals showing karyotypes of both races were excluded from the analysis. Thus, for the Hällefors race we considered localities 1-10 excluding site 8 , and for the Uppsala race we included localities 11 and 16-23.

A hierarchical approach using $F$-statistics (Weir, 1996) was chosen to estimate the number of migrants $(\mathrm{Nm})$ among localities within and between races using the formula $F=[1 /(4 N m d /(d-1)+1)]$ (Slatkin \& Voelm, 1991). The correction $d$ for the number of demes (localities in each race) is not squared because in our case $F$-estimates are based on the variance component method (see eqn 13, Rousset, 1996) (J. Goudet, pers. comm.). In this way, the heterozygote deficits within samples (localities) $\left(F_{\mathrm{IS}}\right)$, between samples within a race $\left(F_{\mathrm{SR}}\right)$ and between samples among races $\left(F_{\mathrm{RT}}\right)$ were estimated. Here the number of migrants among samples within races is calculated from $F_{\mathrm{SR}}$ and gene flow between the two races from $F_{\mathrm{RT}}$. For all calculations the computer package s-PLus (S-Plus, 1995) was used (J. Goudet, pers. comm.). Levels of significance for $F_{\mathrm{SR}}$ were estimated by running FSTAT for both races independently, combining the $P$-values of $F_{\mathrm{ST}}$ for each locus and overall applying Fisher's procedure (see above). For $F_{\mathrm{RT}}$, individuals of each race were pooled to one population and the $P$-value of $F_{\mathrm{ST}}$ taken. In both cases, 5000 permutation steps were performed. Hierarchical $R$-estimates were obtained by an analysis of variance where alleles are analysed according to their number of repeats (Rousset, 1996). $R$-statistics generally show a great variance and therefore no test of significance was carried out.

To investigate further the effect of the river on genetic differentiation we estimated $F_{\mathrm{ST}}$ for five pairs of localities separated by the river $(8 / 11,9 / 15,14 / 15$, $13 / 17$ and 12/16) and compared it with the values of five pairs of localities which are not separated by a geographical barrier $(5 / 6,6 / 7,10 / 14,15 / 18$ and 18/19). The geographical distance between each locality ranged from 0.7 to $2.0 \mathrm{~km}$. Overall values for $F_{\mathrm{ST}}$ were obtained by taking the mean, and Fisher's procedure was applied for $P$-values.

The associations between geographical distances and values of either $F_{\text {ST }}$ or $R_{\mathrm{ST}}$ for pairs of samples can be tested for significance by performing

(c) The Genetical Society of Great Britain, Heredity, 82, 79-88. 
two-matrix Mantel tests (Mantel, 1967). In this way, it is possible to test if genetic differentiation increases with geographical distance (Slatkin, 1993). We used a method of data analysis involving the regression of $F_{\mathrm{ST}} /\left(1-F_{\mathrm{ST}}\right)$ (or $R_{\mathrm{ST}}$ ) estimates for pairs of populations on the logarithm of geographical distance for populations in two-dimensional habitats (Rousset, 1996). Mantel tests were performed using 5000 randomization steps.

\section{Results}

Genetic polymorphism, temporal changes in allele frequencies and linkage disequilibrium

Most loci display high levels of variation ranging from two to 35 distinct alleles (Table 2). With the exception of locus 16, the observed heterozygosity for each locus is high $(0.58-0.89)$. The observed average heterozygosity over all microsatellite loci is 0.66 . These values are close to the expected ones (gene diversity: 0.63-0.94; average: 0.71). The highest number of race-specific alleles is found for locus $9(N=6)$. Out of 97 alleles detected for both races, six alleles $(6.2 \%)$ are exclusively found in the Hällefors race and eight (8.6\%) in the Uppsala race. The total number of race-specific alleles is 14 $(14.4 \%)$.

Animals collected at the same site over two years, encompassing two generations, were available for only two localities (nos 10 and 20). No significant gene frequency changes over time were observed and the overall change was not significant $(P>0.1$, d.f. $=4)$. The same is true for localities 14 and 15 , where individuals belong to the same generation, but two different years $(P>0.5$, d.f. $=4)$. Genetic

Table 2 Number of alleles ( $k$, total), specific alleles in each race ( $k$, Uppsala and Hällefors) of Sorex araneus, observed heterozygosity $\left(H_{\mathrm{o}}\right)$, expected heterozygosity $\left(H_{\mathrm{e}}\right.$, measured as $\left.1-\Sigma\left(p_{i}\right)^{2}\right)$ and number of individuals analysed at each microsatellite locus; race-specific alleles are defined as occurring exclusively in one race

\begin{tabular}{lcccccc}
\hline & $k$ & $k$ & $k$ & & & \\
Locus & (Total) & (Uppsala) & (Hällefors) & $H_{\mathrm{o}}$ & $H_{\mathrm{e}}$ & $n$ \\
\hline L 9 & 35 & $3(8.6 \%)$ & $3(8.6 \%)$ & 0.89 & 0.94 & 274 \\
L 14 & 23 & - & $2(8.7 \%)$ & 0.82 & 0.91 & 268 \\
L 16 & 2 & - & - & 0.08 & 0.18 & 280 \\
L 45 & 16 & - & $1(6.3 \%)$ & 0.84 & 0.84 & 265 \\
L 67 & 10 & $3(30 \%)$ & - & 0.77 & 0.76 & 282 \\
L 92 & 11 & $2(18.2 \%)$ & - & 0.58 & 0.63 & 272 \\
All loci & 97 & $8(8.6 \%)$ & $6(6.2 \%)$ & 0.66 & 0.71 & 273.5 \\
\hline
\end{tabular}

variation over time at four of the six microsatellite loci used in this study (L9, L16, L45 and L67) was similarly analysed for common shrew populations in France, and no significant gene frequency changes over time were detected (N. Lugon-Moulin, unpubl. data). Therefore, samples from different years were pooled for analysis. Analysis for genotypic linkage disequilibrium resulted in nonsignificant values, indicating no genetic linkage between the six markers used in the present study.

\section{Genetic structuring and migration}

The Hardy-Weinberg exact test for loci over all localities gave significant results for loci 14 and 16 . Tests for single localities resulted in nonsignificant $P$-values, except for site 15 . Locality 15 showed a highly significant deviation from Hardy-Weinberg equilibrium which was, however, caused by loci 9 and 16 only (data not shown). In a first $F$-statistics analysis over all localities irrespective of the chromosome race $(N=22)$, a relatively high value for the within-sample heterozygote deficit $\left(F_{\text {IS }}=0.052\right)$ was observed and was highly significant. A closer inspection of $F_{\text {IS }}$ values for the six loci revealed that locus 16 showed a much higher heterozygote deficit $\left(F_{\mathrm{IS}}=0.54, P<0.001\right)$ as compared to the rest of the microsatellites employed in this study (data not shown). This might indicate the presence of null alleles or selective constraints at this locus. A similar pattern for this locus was reported in a previous study (Wyttenbach \& Hausser, 1996b). Therefore, we excluded locus 16 from further analysis. The low but significant $F_{\mathrm{ST}}$ value over all localities (0.017) suggests weak genetic structuring.

Estimates of $F$ - and $R$-statistics for each locus over all populations in each chromosome race are given in Table 3. Values of $F_{\text {IS }}$ for each locus are close to zero and nonsignificant in both races with the exception of locus 14 . The overall value of $F_{\text {IS }}$ for the Hällefors race $\left(F_{\text {IS }}=0.037, \quad P<0.05\right)$ becomes nonsignificant if locus 14 is excluded $\left(F_{\mathrm{IS}}=0.013, P>0.263\right)$. Again, $R_{\mathrm{IS}}$ for locus 14 displays the highest values of all loci in both races. Estimates of $F_{\mathrm{ST}}$ are similarly small in both races (Hällefors: $F_{\mathrm{ST}}=0.011$; Uppsala: $F_{\mathrm{ST}}=0.009$ ), significantly different from zero and close to the overall $F_{\text {ST }}(0.017)$. In the Hällefors race, $F_{\text {ST }}$ values for each locus and overall are lower compared to estimates of $R_{\mathrm{ST}}$, except for locus 14 . This trend is absent in the Uppsala race, where $F_{\mathrm{ST}}$ for two loci and the overall value is higher than $R_{\mathrm{ST}}$ (Table 3 ).

The results of the hierarchical $F$ - and $R$-statistics analyses are presented in Table 4. Intraracial struc- 
Table 3 Estimates of $F$ - and $R$-statistics for each locus over all populations calculated separately for each chromosome race (Hällefors and Uppsala) of Sorex araneus

\begin{tabular}{|c|c|c|c|c|c|c|}
\hline Locus & $F_{\text {IS }}$ & $F_{\mathrm{ST}}$ & $F_{\text {IT }}$ & $R_{\mathrm{IS}}$ & $R_{\mathrm{ST}}$ & $R_{\mathrm{IT}}$ \\
\hline \multicolumn{7}{|c|}{ Chromosome race Hällefors } \\
\hline L 9 & 0.035 & 0.040 & 0.039 & -0.091 & 0.045 & -0.042 \\
\hline L 14 & $0.118 * *$ & 0.011 & $0.127 * * *$ & 0.162 & -0.003 & 0.159 \\
\hline $\mathrm{L} 45$ & -0.049 & 0.007 & -0.042 & -0.011 & 0.009 & -0.002 \\
\hline L 67 & 0.012 & $0.032^{*}$ & 0.044 & -0.190 & 0.081 & -0.093 \\
\hline L 92 & 0.063 & 0.001 & 0.063 & -0.217 & 0.033 & -0.177 \\
\hline All loci & $0.037^{*}$ & $0.011^{*}$ & $0.047 * *$ & -0.028 & 0.030 & 0.003 \\
\hline \multicolumn{7}{|c|}{ Chromosome race Uppsala } \\
\hline L 9 & 0.017 & 0.003 & 0.019 & 0.158 & -0.016 & 0.145 \\
\hline L 14 & $0.123 * *$ & 0.014 & $0.135 * * *$ & 0.192 & 0.022 & 0.210 \\
\hline $\mathrm{L} 45$ & -0.058 & 0.012 & -0.046 & -0.158 & 0.032 & -0.122 \\
\hline L 67 & -0.014 & 0.010 & -0.004 & 0.021 & 0.029 & 0.050 \\
\hline L 92 & -0.057 & 0.006 & -0.051 & 0.024 & -0.038 & -0.013 \\
\hline All loci & 0.009 & $0.009 *$ & 0.018 & 0.099 & 0.001 & 0.101 \\
\hline
\end{tabular}

$* P<0.05, * * P<0.01, * * * P<0.001$ for $F$-statistics.

turing for $F$-statistics is highly significant $\left(F_{\mathrm{SR}}=0.0207\right)$ and close to $R_{\mathrm{SR}}(0.0214)$. Three out of five loci (L9, L14 and L67) give significant results for $F_{\mathrm{SR}}$. Surprisingly, both values for inter-racial genetic structuring $\left(F_{\mathrm{RT}}=0.0026 ; R_{\mathrm{RT}}=0\right)$ are lower than estimates for within-race genetic differentiation. Here, two loci (L 9 and L 14) and the overall value for $F_{\mathrm{RT}}$ are significant. This indicates less pronounced genetic differentiation between the two chromosome races compared to genetic subdivision within a race. We estimated the number of migrants from $F$ - and $R$-statistics, respectively. The migration rate between populations within a race gives a value of 11 migrants for $F_{\mathrm{SR}}$ and 10.6 for $R_{\mathrm{SR}}$. The number of migrants exchanged between the two races is 92 animals per generation using $F_{\mathrm{RT}}$. Nm cannot be estimated from $R_{\mathrm{RT}}$ because its value is zero (Table 4).

\section{Effect of river and isolation by distance}

The mean $F_{\mathrm{ST}}$ value for sites separated by the river is 0.0152 and combined $P$-values gave a high overall significance $(P<0.001)$. Similarly, the average $F_{\mathrm{ST}}$ value for pairs of populations not divided by the river is 0.0226 and significant $(P<0.001)$. Mantel tests on either pairwise $F_{\mathrm{ST}}$ or $R_{\mathrm{ST}}$ matrices against the geographical distance matrix did not reveal any

Table 4 Values of a hierarchical $F$ - and $R$-statistics analysis carried out on Sorex araneus for each locus and over all loci; letter subscript $I$ stands for individuals, $S$ for samples, $R$ for races and $T$ for total

\begin{tabular}{|c|c|c|c|c|c|c|c|c|}
\hline \multirow[t]{2}{*}{ Locus } & \multicolumn{4}{|c|}{ Hierarchical values for $F$} & \multicolumn{4}{|c|}{ Hierarchical values for $R$} \\
\hline & $F_{\text {IS }}$ & $F_{\mathrm{SR}}$ & $F_{\mathrm{RT}}$ & $F_{\text {IT }}$ & $R_{\mathrm{IS}}$ & $R_{\mathrm{SR}}$ & $R_{\mathrm{RT}}$ & $R_{\mathrm{IT}}$ \\
\hline L 14 & 0.0801 & $0.0201 * * *$ & $0.0146 * *$ & 0.1118 & 0.1992 & 0.0321 & 0.0084 & 0.2314 \\
\hline L 45 & -0.0027 & 0.0034 & -0.0006 & 0.0001 & 0.0092 & 0.0075 & -0.0045 & 0.0122 \\
\hline All loci & 0.0258 & $0.0207 * * *$ & $0.0026 * *$ & 0.0232 & 0.0507 & 0.0214 & 0.0000 & 0.0705 \\
\hline
\end{tabular}

${ }^{*} P<0.05, * * P<0.01, * * * P<0.001$ for $F_{\mathrm{SR}}$ and $F_{\mathrm{RT}}$. 
significant positive association. The observed matrix correlation using $F_{\mathrm{ST}}(r=-0.2, P=0.97)$ or $R_{\mathrm{ST}}$ $(r=0.05, P=0.31)$ is nonsignificant.

\section{Discussion}

The high genetic variability at, and absence of linkage between, the five microsatellite markers employed, make them an excellent tool to study genetic structuring at the small geographical scale where the Hällefors and Uppsala races meet and hybridize. Stockley et al. (1993) showed that female common shrews are highly promiscuous and regularly mate with close relatives. Based on this result they argued that multiple mating in the common shrew may be a strategy to reduce inbreeding. In our study, values over all loci for $F_{\text {IS }}$ are never significantly different from zero, suggesting random mating within localities.

Considering each race separately, the reduction of heterozygosity as a result of geographical subdivision is weak, but nevertheless significantly different from zero $\left(F_{\mathrm{ST}}=0.009-0.011, P<0.05\right)$. This indicates that the samples for each race cannot be regarded as collected from a panmictic population. We find no isolation by distance at the geographical level sampled.

Looking at the hierarchical analysis, we find that genetic differentiation on an intraracial scale is higher than on an inter-racial level. The number of migrants exchanged within chromosome races is about 11 animals per generation, estimated from $F_{\mathrm{SR}}$ and $R_{\mathrm{SR}}$. The $\mathrm{Nm}$ value between the chromosome races is as high as 92, estimated from $F_{\mathrm{RT}}$. This result is surprising because migration between races is not expected to be higher than within races, but similar, assuming no geographical barrier or mating preferences. However, $\mathrm{Nm}$ estimates from $F_{\mathrm{ST}}$ made for each chromosome race separately vary between 22 and 28 immigrants per generation. This indicates a three- to fourfold difference in migration within compared to between races, a degree of variation that can be expected for rough estimates such as $\mathrm{Nm}$. These results suggest that the river is not a serious barrier to gene flow reducing introgression between the two chromosome races. This is also supported by the direct comparison of sites separated by the river with sites that are not, where similar $F_{\mathrm{ST}}$ values are found.

These findings are congruent with a study on the contact zone of the common shrew between the Cordon and Valais races in the French western Alps, where rivers did not have a significant effect on reducing gene flow (Lugon-Moulin et al., 1996).
But then, how is extensive gene flow between the Hällefors and Uppsala race compatible with the steep cline of race-specific chromosomes decreasing towards the river? Hybrid zones are likely to be 'attracted' to a local geographical barrier or a region of low density (Barton \& Hewitt, 1981). For mammals, chromosomal races commonly meet at local geographical barriers, such as rivers (Searle, 1993). A slight reduction in dispersal across a river is perhaps sufficient to 'trap' a race-specific chromosomal front. However, such a scenario is difficult to imagine in our study because of the high values for $\mathrm{Nm}$ found between races. The higher between-races $\mathrm{Nm}$ could be explained by some aspects of the reproductive behaviour or migratory habits of shrews (e.g. shrews are good swimmers), but not the narrow width of the cline.

A possible reason for this discrepancy is that some animals showing a karyotype of a pure parental form carry microsatellite alleles from a 'hybrid genome'. If an $F_{1}$ hybrid between the Uppsala and Hällefors races backcrosses with an individual exhibiting a karyotype of a pure parental form, $50 \%$ of the backcross offspring will show a race-specific karyotype although carrying $50 \%$ of the $F_{1}$ hybrid genome. Apparent $F_{1}$ hybrids between the Hällefors and Uppsala races were detected at very distant localities from the centre of the hybrid zone (Table 1 and Fig. 1). Thus at these sites, individuals showing for example a Hällefors karyotype, but carrying genetic material from the Uppsala race, are expected to be frequent. Therefore, the chromosomal cline is steeper than expected from the high level of migration found in the hybrid zone. Lower fecundity in heterozygous females compared to homozygotes could be an alternative explanation for the maintenance of the chromosomal hybrid zone. In a study on fertility in female common shrews, Wallace \& Searle (1994) concluded that fecundity (the total number of offspring) could be lower for heterozygotes (having fewer oocytes and a shorter lifespan than homozygotes).

The low number of race-specific microsatellite alleles (14 out of 97, 14.4\%) found in the present work indicates that the two races are genetically close, and contrasts with the study on the contact zone between the races Valais and Cordon in Switzerland (Lugon-Moulin et al., 1996). There, the total number of alleles detected in both races was lower $(N=78)$, but $59 \%$ were race-specific (Lugon-Moulin et al., 1996). Indeed, the Cordon and Valais chromosome races are known to be genetically very distinct, as shown for morphological characters (Hausser, 1991), by two protein markers (Brünner \& Hausser, 
1996) and mtDNA clones (Taberlet et al., 1994). However, because of the limited number of animals analysed in the study of Lugon-Moulin et al. (1996) $(N=77)$, it is possible that some specific alleles of one race were missed in the other.

Chromosomal hybrid zones are often believed to be the result of secondary contact. If we advocated a secondary contact between the Uppsala and Hällefors races after isolation and fixation of race-specific chromosomes in allopatry, microsatellites would be sensitive markers to detect genetic differentiation between the two races. Then, the low level of genetic differentiation on an inter-racial level would suggest short isolation in the past. Alternatively, high gene flow across the hybrid zone could have allowed 'homogenization' of the two genomes, which were genetically more distinct when they met in the past. However, keeping in mind that our microsatellite analysis was carried out in a zone of strong hybridization, only animals of pure races should be analysed to infer the true genetic relationship between the races. Such animals are expected to occur more distantly from the centre of the hybrid zone and could be detected by race-specific markers other than chromosomes (e.g. mtDNA).

Under a stepwise mutation model (SMM), values of $F_{\mathrm{ST}}$ are expected to be smaller compared to values of $R_{\mathrm{ST}}$ and hence do overestimate migration (Slatkin, 1995). $F$ - and $R$-statistics are now estimated and compared with their theoretical expectations in more and more studies of natural populations (e.g. Ross et al., 1997; Viard et al., 1997). So far, microsatellites do not seem always to follow an SMM, supporting the unique use of $R$-statistics. Here, we found that on an intraracial scale, $F_{\mathrm{ST}}$ is, as expected, smaller than $R_{\mathrm{ST}}$ in the Hällefors race but not in the Uppsala race. For the hierarchical analysis, values for within-race differentiation $\left(F_{\mathrm{SR}}\right.$ and $\left.R_{\mathrm{SR}}\right)$ are almost identical, whereas for the estimates between races $F_{\mathrm{RT}}$ is higher than $R_{\mathrm{RT}}$. The variation among loci for $R_{\mathrm{ST}}$ values in each race shows a higher variance compared with values for $F_{\mathrm{ST}}$, something that is expected when migration is high (Slatkin, 1995). This is, however, not the case for estimates of the hierarchical analysis. It is likely that these discrepancies are caused by the underlying mutation patterns that can differ from locus to locus. In a population genetic study by Wyttenbach et al. (in press) using the same loci (four out of six), neither the stepwise mutation model (SMM) nor the infinite allele size model (IAM) accounted for the variation detected at each locus.

In conclusion, the simultaneous use of hierarchical $F$-and $R$-statistics allowed us to estimate migration across the hybrid zone. We found no evidence that the river is a barrier to gene flow, something that would have been expected considering the steep cline of race-specific chromosome markers (Narain \& Fredga, 1996). It seems that the chromosomal cline is 'trapped' by the river despite a high level of introgression between races. Sampling at more distant localities and the use of race-specific genetic markers other than chromosomes will be necessary to understand the phylogenetic history of this hybrid zone.

\section{Acknow ledgements}

We thank H. Tegelström, J. B. Searle, C. G. Thulin, N. Lugon-Moulin, M. Carlsson and M. Lascoux for helpful discussions and constructive criticism on the manuscript. Many thanks go to J. Goudet for help with statistical analysis. We are grateful to $\mathbf{J}$. Hausser and F. Balloux for providing access to the oligonucleotides used in this study. This work was financially supported by the Nilsson-Ehle Foundation and the Swedish Natural Science Research Council.

\section{References}

BALlOUX, F., ECOFFEY, E., FUMAGAlli, L., GOUDET, J., WYTTENBACH, A. AND HAUSSER, J. 1998. Microsatellite conservation, polymorphism and GC content in shrews of the genus Sorex (Insectivora, Mammalia). Mol. Biol. Evol., 15, 473-475.

BANASZEK, A. 1994. The structure of the contact zone between the chromosomal races Druzno and Legucki Mlyn in the common shrew (Sorex araneus) in northeastern Poland: preliminary results. Folia Zoologica, $\mathbf{4 3}$ (suppl. 1), 11-19.

BARTON, N. H. AND HEWITT, G. M. 1981. Hybrid zones and speciation. In: Atchley, W. R. and Woodruff, D. S. (eds) Evolution and Speciation: Essays in Honour of M. J. D. White, pp. 109-145. Cambridge University Press, Cambridge.

BRÜNNER, H. AND HAUSSER, J. 1996. Genetic and karyotypic structure of a hybrid zone between the chromosomal races Cordon and Valais in the common shrew, Sorex araneus. Hereditas, 125, 147-158.

FEDYK, s., ZAJKOWSKA, M. AND CHETNICKI, w. 1993. Study of a contact between two chromosomally monomorphic races of Sorex araneus L. (common shrew). Heredity, 71, 221-226.

FREDGA, K. 1996. The chromosome races of Sorex araneus in Scandinavia. Hereditas, 125, 123-135.

FRYKMAN, I. AND BENGTSSON, B. O. 1984. Genetic differentiation in Sorex. III Electrophoretic analysis of a hybrid zone between two karyotypic races in Sorex araneus. Hereditas, 100, 259-270.

(C) The Genetical Society of Great Britain, Heredity, 82, 79-88. 
GOLDSTEIN, D. B. AND POLLOCK, D. D. 1997. Launching microsatellites: a review of mutation processes and methods of phylogenetic inference. J. Hered., 88, $335-342$.

GOUDET, J. 1995. FSTAT (version 1.2): A computer program to calculate $F$-statistics. J. Hered., 86, 485-486.

HARRISON, R. G. 1990. Hybrid zones: windows on evolutionary processes. In: Futuyma, D. and Antonovics, J. (eds) Oxford Surveys in Evolutionary Biology, vol. 7, pp. 69-128. Oxford University Press, Oxford.

HAUSSER, J. 1991. Relationships between chromosome races and species of Sorex of the araneus group in the western Alps. In: Hausser, J. (ed.) The Cytogenetics of the Sorex araneus Group and Related Topics, pp. 79-98. Mem. Soc. Vaud. Sci. Nat., vol. 19. Société vaudoise des Sciences naturelles, Lausanne.

HEWITT, G. M. 1988. Hybrid zones - natural laboratories for evolutionary studies. Trends Ecol. Evol., 3, 158-167.

KING, M. 1993. Species Evolution: the Role of Chromosome Change. Cambridge University Press, Cambridge.

LUGON-MOULIN, N., WYTTENBACH, A., BRÜNNER, H., GOUdET, J. AND HAUSSER, J. 1996. Study of gene flow through a hybrid zone in the common shrew (Sorex araneus) using microsatellites. Hereditas, 125, 159-168.

LUKACOVA, L., PIALEK, J. AND ZIMA, J. 1994. A hybrid zone between the Ulm and Drnholnec karyotypic races of Sorex araneus in the Czech Republic. Folia Zoologica, 43 (suppl. 1), 53-61.

MANTEL, N. 1967. The detection of disease clustering and generalized regression approach. Cancer Res., 27, 209-220.

NARAIN, Y. AND FREDGA, K. 1996. A hybrid zone between the Hällefors and Uppsala chromosome races of Sorex araneus in central Sweden. Hereditas, 125, 137-145.

NARAIN, Y. AND FREDGA, K. 1997. Meiosis and fertility in common shrews, Sorex araneus, from a chromosomal hybrid zone in central Sweden. Cytogenet. Cell Genet., 78, 253-259.

NEI, M. 1987. Molecular Evolutionary Genetics. Columbia University Press, New York.

RATKIEWICZ, M. A., BANASZEK, A. AND LOBODZINSKA, J. 1994. Isozyme variation in the common shrew (Sorex araneus) from the hybrid zone between the chromosomal races Druzno and Legucki Mlyn: preliminary results. Folia Zoologica., 43 (suppl. 1), 21-28.

RAYMOND, M. AND ROUSSET, F. 1995. GENEPOP (version 1.2): Population genetics software for exact tests and ecumenicism. J. Hered., 86, 248-249.

ROSS, K. G., KRIEGER, M. J. B., SHOEMAKER, D. D., VARGO, E. L. AND KELLER, L. 1997. Hierarchical analysis of genetic structure of native fire ant populations: results from three classes of molecular markers. Genetics, 147, 643-655.

ROUSSET, F. 1996. Equilibrium values of measures of population subdivision for stepwise mutation processes. Genetics, 142, 1357-1362.

ROY, M. S., GEFFEN, D., SMITH, D., OSTRANDER, E. A. AND WAYNE, R. K. 1994. Patterns of differentiation and hybridization in North American wolflike canids, revealed by analysis of microsatellite loci. Mol. Biol. Evol., 11, 553-570.

SEARLE, J. B. 1993. Chromosomal hybrid zones in eutherian mammals. In: Harrison, R. G. (ed.) Hybrid Zones and the Evolutionary Process, pp. 309-353. Oxford University Press, New York.

SLATKIN, M. 1993. Isolation by distance in equilibrium and non-equilibrium populations. Evolution, 47, 264-279.

SLATKIN, M. 1995. A measure of population subdivision based on microsatellite allele frequencies. Genetics, 139, 457-462.

SLATKIN, M. AND VOELM, L. 1991. $F_{\mathrm{ST}}$ in a hierarchical island model. Genetics, 127, 627-629.

SOKAL, R. R. AND ROHLF, F. J. 1995. Biometry, 3rd edn. W. H. Freeman, San Francisco.

s-Plus. 1995. Guide to Statistical and Mathematical Analysis, version 3.3. StatSci., a division of MathSoft, Inc., Seattle, WA.

STOCKLEY, P., SEARle, J. B., MACDONALD, D. W. AND JONES, C. S. 1993. Female multiple mating behaviour as a strategy to reduce inbreeding. Proc. R. Soc. B, 254, 173-179.

SZALAY, K. A., FEDYK, S., BANASZEK, A., CHETNICKI, W. AND RATKIEwicz, M. A. 1996. A hybrid zone between two chromosome races of the common shrew, Sorex araneus, in eastern Poland: preliminary results. Hereditas, 125, 169-176.

TABERlet, P., FUMAGAlli, L. AND HAUSSER, J. 1994. Chromosomal versus mitochondrial DNA evolution: tracking the evolutionary history of the southwestern European populations of the Sorex araneus group (Mammalia, Insectivora). Evolution, 48, 623-636.

VIARD, F., JUSTY, F. AND JARNE, P. 1997. Population dynamics inferred from temporal variation at microsatellite loci in the selfing snail Bulinus truncatus. Genetics, 146, 973-982.

WAllace, B. M. D. AND SEARle, J. B. 1994. Oogenesis in homozygotes and heterozygotes for Robertsonian chromosomal rearrangements from natural populations of the common shrew, Sorex araneus. J. Reprod. Fert., 100, 231-237.

WEIR, B. s. 1996. Genetic Data Analysis. Sinauer Associates, Sunderland, MA.

WEIR B. S. AND COCKerham, C. C. 1984. Estimating $F$-statistics for the analysis of population structure. Evolution, 38, 1358-1370.

WOJCIK, J. M. AND SEARLE, J. B. 1988. The chromosome complement of Sorex granarius - the ancestral karyotype of the common shrew Sorex araneus? Heredity, 61, 225-229.

WRIGHT, s. 1951. The genetical structure of populations. Ann. Eugen., 15, 323-354.

WYTTENBACH, A. AND HAUSSER, J. 1996a. Microsatellites in Sorex araneus (Insectivora): highly polymorphic markers for population genetic studies within and between chromosome races. Hereditas, 125, 177-181.

WYTTENBACH, A. AND HAUSSER, J. 1996b. The fixation of metacentric chromosomes during the chromosomal 
evolution in the common shrew (Sorex araneus, Insectivora). Hereditas, 125, 209-217.

WYTTENBACH, A., FAVRE, L. AND HAUSSER, J. 1997. Isolation and characterisation of simple sequence repeats in the genome of the common shrew. Mol. Ecol., 6, 797-800.

WYTTENBACH, A., GOUDET, J., CORNUET, J. M. AND HAUSSER
J. 1999. Microsatellite variation reveals low genetic subdivision in a chromosome race of Sorex araneus (Mammalia, Insectivora). J. Hered. (in press).

ZIMA, J., FEDYK, S., FREDGA, K., HAUSSER, J., MISHTA, A., SEARLE, J. B. ETAL. 1996. The list of the chromosome races of the common shrew (Sorex araneus). Hereditas, 125, 97-107. 